News

\title{
The effect of psychological counseling on mental health
}

\begin{abstract}
This research has been study the counselling effect on PG students' mental health. The population were postgraduate students of VNSGU, Surat, who came for counselling sessions to the psychological counselling centre. They are 108 Students. From this population, 30 students were selected with random sampling method. Questionnaire made by researcher and Unstructured interview were used for data gathering. Information analysed with the qualitative method. Results showed that counselling is much helpful for postgraduate students. They become more relax; can focus on their goal, aware about their strength and weakness. Students can plan their schedule according to the goal. They learn how to manage their emotions. This research showed that counselling services should be provided in every educational institute. A qualified person should be appointed for counselling to students and when they need help, he should be available for students so they can freely consult their counsellor.
\end{abstract}

Keywords: psychological counseling, mental health, emotions, neurotic, psychotic
Volume 7 Issue 3 - 2017

Kirti Matliwala

Department of Education, Veer Narmad South Gujarat University, India

Correspondence: Department of Education, Veer Narmad South Gujarat University, India, Tel 9328962178 , Email kiriti_matliwala@yahoo.com

Received: December 0I, 2016 | Published: February 15, 2017

\section{Introduction}

Person has major concerns on his mind that may interfere with his success, happiness, and satisfaction in the life. When we think about students, their mind may major role in their academic success. Their mental balance is needed in many situations. Such as family problems, homesickness, identity, loneliness, loss of motivation, pain, problems with food or body image. When student cannot cope up with the situations, he loses his mental health. In developing countries, the decline of mental health has increased and neglects the social dimensions, family and personal touches remained the irreversible effects. ${ }^{1}$ It has been reported that person-centred counselling is effective for clients with common mental health problems such as anxiety and depression. ${ }^{2}$

\section{What is counselling?}

Counselling is a way of helping people to solve their own emotional, social, personal or interpersonal problems. Counselling is not giving advice, or solving your problems on behalf of you. In counselling counsellor guides you to look at problems with objective way. He shows different dimension to understand the situation. He helps you to know your strengths and weaknesses without being judgemental. Counselling involves the exploration problems in an environment that is both supportive and objective. It also involves the identification of alternative courses of action that might solve a problem. Counsellor suggests strategies for managing and altering patterns of upsetting thoughts, feelings and behaviour.

\section{What is mental health?}

Mental health is a key part of our successful life and our overall well-being. The World Health Organization (WHO) states that there is no health without mental health. Our capacity is depend on our mental health. It is the source of our collective and individual ability as people to reach our full potential. Mental health refers to the way in which we are aware of our own abilities so we can cope well with the difficulties of life. If person is emotionally balanced than, he can capable of working productively and giving a contribution to his or her community. A range of factors can affect our emotional wellbeing. These include genetics, prolonged stress, physical illness and shocking events. Environmental issues such as the economic, political and social climate can also have an impact.

\section{Types of mental health issues}

Mental health issues can have a deep impact on how we think, feel and behave. They can range from our daily worries we have from time to time, to serious problems. According to the Mental Health Foundation (MHF), there are two main types of mental health problems.
a. Neurotic symptoms
b. psychotic symptoms

\section{Neurotic symptoms}

Individuals that have 'common mental health issues' are very likely to have neurotic symptoms. These are harsh versions of 'normal' emotions, such as stress, sadness and anxiety. We all feel down or worried every now and then, but if those emotions start affecting daily life, it may be a sign of a mental health problem. If mental health issues are ignored, it can lead to further problems.

Mental health issues with neurotic symptoms include: Depression, anxiety, obsessive-compulsive disorder (OCD), phobias, posttraumatic stress disorder (PTSD), panic disorders.

\section{Psychotic symptoms}

Mental health issues with psychotic symptoms are less common. Psychotic symptoms interfere with a person's perception of reality. It may include hallucinations of the things. Such as seeing, smelling, hearing or feeling things that no one else can. People experiencing psychosis may form unrealistic views about themselves, other people and the world around them.

Mental health issues with psychotic symptoms include: Schizophrenia, eating disorders, substance abuse, bipolar disorder, Personality disorder.

There is no set list when it comes to the signs and symptoms of mental health problems. Some general signs to look out for include are below. 
Withdrawing from society, Teary, Drop in productivity, Weightloss or weight gain, Dirty or untidy, Tired, Difficulty speaking, spending too much money.

\section{Rational of the study}

In research on counselling services conducted by some researchers. Razmi $^{3}$ concluded that counselling services to help students have been effective. Baum \& Fleming ${ }^{4}$ showed that counselling services in schools have been useful to resolve the academic problems of students. Khodaei ${ }^{5}$ showed that group counselling has been effective in decreasing student's anxiety. In present study researcher has focused on effect of counselling on particular group, which is postgraduate students. Apart from academic researcher has tried to study effect on mental health.

\section{Objective}

The main objective of the present research is to study the effect of psychological counselling on the mental health of postgraduate students.

\section{Methods}

This research method was survey. Psychological counselling service was provided to postgraduate students. There were two types of counselling; individual counselling and group counselling. Number of students who came for counselling during September 2013 to December 2015 is as below.

\section{Common counseling concerns were}

\author{
i. Anxiety \\ ii. Depression, \\ iii. Sadness \& Loneliness \\ iv. Feeling Hopeless \\ v. Self-Esteem \& Confidence \\ vi. Relationship \& Family Issues \\ vii. Suicidal Thoughts \\ viii. Adjustment \& Homesickness \\ ix. Feelings of Anger
}

Based on random sampling, 30 cases of students (20 girls and 10 boys) were randomly selected as samples. Data were collected by questionnaire designed by researcher and by unstructured interview was taken by researcher. Qualitative method was used for data analysis. $^{6}$

\section{Findings}

Students come to counselling to talk about a wide range of issues. Such as stress, family issues, depression, anxiety, relationship issues. Students mention that a helpful way of dealing with problematic situations and feelings is to start by talking them with counsellor. Students do not have lot of difficulties or medical problems, but they come with normal life problems, such as family or relationship issues, homesickness or anxiety about their work or academic performance. Students say that counseling enhance their ability to meet the challenges they face so they can enjoy their life.
Investigation reveals that students who are guided by counselors find themselves more confident and good in academic performance. They can do well in their study. There is positive effect of counseling during postgraduate study days in the university. Results showed that counselling is much helpful for postgraduate students. They become more relax; can focus on their goal, aware about their strength and weakness. Students can plan their schedule according to the goal. They learn how to manage their emotions. Counsellor motivates them to do better and innovative way. By counselling sessions, their insight is developed to see the situation in different way.

Students apply new techniques for learning according to their abalities. Students suggest that counselling services should be provided in every educational institute. A counsellor should be appointed for counselling to students and when they need help, he should be available for students so they can freely consult their counsellor.

Counseling is of great importance to the education system. Government should establish counseling services units in every institution. This will better both the lives of the individual students, the education system and the general society.

\section{Conclusion}

In recent years, mental health of students becomes matter of priority in education organization. The findings of this study indicate that every educational institute should have counsellor to guide and to help the students. He can make good environment, which is motivational for students' growth. The counselling services to students and their normal self are good predictors for mental health promotion.

\section{Acknowledgments}

None.

\section{Conflicts of interest}

Author declares there are no conflicts of interest.

\section{Funding}

None.

\section{References}

1. Dadsetan P. Stress. Roshd, Tehran, Iran. 1998.

2. Ward E, King M, Lloyd M, et al. Randomised controlled trial of nondirective counselling, cognitive-behaviour therapy, and usual general practitioner care for patients with depression. I: Cost-effectiveness. BMJ. 2000;321(7273):1389-1392.

3. Razmi A. Success factors in Ardebil province consultants [research project]. Ardebil: Education Research Council. 1999.

4. Baum A, Fleming I. Implications of psychological research on stress and technological accidents. Am Psychol. 1993;48(6):665-672.

5. Khodaei KS. The effect of group counselling approach with emphasis on reducing anxiety in connection dialog Mshkynshahr high school students. [research project]. Ardebil: Education Research Council. 1997.

6. Roger B, Emma B, Helen A, et al. A naturalistic longitudinal evaluation of counselling in primary care. Counselling Psychology Quarterly. 2002;15(4):359-373. 